\title{
Dikkat Eksikliği ve Hiperaktivite Bozukluğu (DEHB) Olan Çocukların Fiziksel Aktivite Düzeyleri
}

\section{Physical Activity Levels of Children with Attention Deficit and Hyperactivity Disorder (ADHD)}

\author{
Melike Karadağ $\breve{1}^{*}$ \\ ${ }^{1}$ Bezmialem Vakıf Üniversitesi Sağlık Bilimleri Enstitüsü Bursa, Türkiye \\ e-mail: karadagmelike@outlook.com.tr \\ ORCID: 0000-0001-9508-147X \\ *Sorumlu yazar/ Corresponding Author: Melike Karadağ \\ Gönderim Tarihi / Received: 21.04.2021 \\ Kabul Tarihi / Accepted: 11.06.2021 \\ DOI: $10.34087 /$ cbusbed. 925366
}

\begin{abstract}
Giriş ve Amaç: Dikkat eksikliği ve hiperaktivite bozukluğu (DEHB) çocuklukta ve ergenlikte sık rastlanılan bir problemdir. Bu problem, öğrencilerin davranışlarını ve okul başarılarını olumsuz yönde etkilemektedir. Bu çalışmada DEHB tanılı ilk ve ortaokul öğrencilerinin fiziksel aktivite düzeylerinin (FAD) araştırılması amaçlanmıştır.

Gereç ve Yöntemler: Araştırma Bursa/Nilüfer ilçesindeki ilkokul ve ortaokullarda okuyan gönüllü bireyler üzerinden gerçekleştirildi. 05.02.2018-20.04.2018 tarihleri arasında sürdürülen araştırmaya 8-14 yaş grubuna giren 39 DEHB tanılı ve 41 sağlıklı öğrenci katıldı. Veri toplamak için çalışma ve kontrol grubunda yer alan öğrencilerin demografik, kişisel, fiziksel ve klinik bilgileri kaydedildi. "Çocuklar için Fiziksel Aktivite Ölçeğii” (ÇFAÖ) kullanılarak tüm bireylerin fiziksel aktivite düzeyleri ölçüldü.

Bulgular: DEHB tanılı kız/erkek öğrenci oranı yaklaşık 1/4 bulundu. Çalışma ve kontrol grubunda boy, kilo ve vücut kitle indeksleri \%50 persantil bulundu. DEHB tanılı öğrenciler daha fazla sağlıklı besin tükettiler $(\mathrm{p}<0,05)$. Çalışma grubunun teneffüslerdeki, günlük boş zamanlarındaki ve hafta sonu fiziksel aktivite düzeyleri kontrol grubu öğrencilerine göre daha yüksek bulundu $(p<0,05)$. DEHB Tiplerine göre öğrencilerin ÇFAÖ özet skorları değerlendirildiğinde, fiziksel aktivitenin Tip-I'de en düşük, Tip-II'de en yüksek olduğu saptandı.

Sonuç: DEHB tanılı ilkokul ve ortaokul öğrencilerinde okul içi ve okul sonrası boş zamanlardaki fiziksel aktivite düzeyleri kontrol grubu öğrencilerine göre daha yüksek görülmüştür.
\end{abstract}

Anahtar kelimeler: Çocuk, Dikkat Eksikliği Hiperaktivite Bozukluğu, Fiziksel Aktivite Düzeyi.

\section{Abstract}

ObjectiveAttention deficit and hyperactivity disorder (ADHD) is a common problem in childhood and adolescence. This problem affects students' behavior and school success negatively. In this study, it was aimed to investigate the physical activity levels (PAL) of primary and secondary school students diagnosed with ADHD.

Materials and Methods The research was carried out on volunteer individuals studying in primary and secondary schools in Bursa / Nilüfer district. 39 ADHD diagnosed and 41 healthy students who were in the 8-14 age group participated in the study, which was carried out between 05.02.2018-20.04.2018. Demographic, personal, physical and clinical information of the students in the study and control groups were recorded to collect data. Physical activity levels of all individuals were measured using "The Physical Activity Questionnaire for Children" (PAQ-C).

Results: The ratio of female/male students diagnosed with ADHD was nearly $1 / 4$. Height, weight and body mass indexes were found to be 50 percentile in the study and control groups. ADHD students consumed more healthy foods $(\mathrm{p}<0.05)$. The physical activity levels of the study group during breaks, daily leisure time and weekend were found to be higher than the control group students $(\mathrm{p}<0.05)$. When the PAQ-C summary scores of the students were evaluated according to ADHD Types, it was found that physical activity was the lowest in Type-I, and the highest in Type-II. Conclusion: Primary and secondary school students diagnosed with ADHD have higher levels of physical activity in leisure time at school and after school than control group students. 
Keywords: Attention Deficit, Hyperactivity Disorder, Physical Activity Level, Child.

\section{Giriş}

Dikkat eksikliği ve hiperaktivite bozukluğu (DEHB), gelişim düzeyi bakımından normal olmayan aşırı hareketlilik, dürtü kontrolünde yetersizlik ve dikkati sürdürme güçlüğü gibi temel belirtilerin gözlemlendiği bir bozukluktur. $\mathrm{Bu}$ sendromun ana özelliği; huzursuzluk, engellemeye yönelik denetim eksikliği sebebiyle davranışlarda veya bilişte ortaya çıkan aksaklık ve dikkat süresinin kısalığıdır. Bu duruma dayalı olarak çocuklarda bulundukları gelişim periyotlarına uymayan dikkatsizlik ve/veya aşırı hareketlilik gözlemlenir [1].

DEHB'nin dünyada yaygınlık oranı çocuklarda \%5-12, yetişkin bireylerde \%4,4'tür. Erkek/kız oranı genel olarak 2/1'dir. Türkiye'de s1klık oranı \%13,8 düzeyindedir. Yurdumuzda yapılan bir araştırmada erkek/kız oranı 3,2 olarak saptanmıştır [2,3].

İlköğretim ve ortaöğretim dönemi çocuklarının \%39'unu etkileyen DEHB'nin kaynağında psikososyal ve biyolojik etkenlerin rol oynadığı düşünülmektedir. Tüm psikiyatrik bozukluklarda olduğu gibi DEHB'ye de eşlik eden pek çok problem gözlenmektedir. Eşlik eden ve üzerinde daha fazla çalışılan bozukluklar; davranış bozukluğu ve karşıt olma-karşı gelme bozukluğudur. Ayrica anksiyete bozuklukları, duygu-durum bozuklukları, madde bağımlılı̆̆ı ve madde kötüye kullanımı gibi bozukluklar da sıkça görülebilmektedir. Bu bozukluk \%30-70 oranında yetişkinlik döneminde de sürerek psikososyal, eğitimsel ve meslek alanlarında işlev kaybına sebep olabilmektedir [4].

DEHB'de sık karşılaşılan klinik semptomlar arasında; okul ve toplum kurallarına uymada zorluklar, derse ilgisizlik, plan yapmada güçlük, aşırı duygusallık ve riskli davranışlarda bulunma vardır. Buna bağlı duygusal, akademik ve sosyal alanlarda görev kaybı gelişir ve tedavi edilmediği takdirde bu durum çocuğun sosyal ve ruhsal gelişimini ve eğitim hayatını negatif yönde etkilemektedir. Bu belirtiler, olguların bazılarında genç erişkinlikte kaybolmakta, bazılarında ise duygusal ve sosyal güçlüklerle devam etmektedir [4].

DEHB oluşumuna beyinin yapısında gelişen değişiklikler, nörokimyasal faktörler, psikososyal ve çevresel faktörlerin neden olduğu düşünülmektedir [1,2]. Ruhsal Bozuklukların Tanısal ve Sayımsal El Kitabı-5'e (DSM-V) göre tanı kriterleri açısından DEHB, dikkat eksikliğinin dominant olduğu tip, hareketlilik ve dürtüselliğin dominant olduğu tip ve kombine tip olarak üçe ayrılmaktadır [3].

Fiziksel aktivite enerji harcayarak yapılan vücut hareketlerini tanımlamak için kullanılan uluslararası bir kavramdır. Günlük yaşamda kasların ve eklemlerin kullanılmasıyla enerji harcanan, nabzı ve solunum hızını arttıran, farklı şiddetlerde yorgunluk ile sonuçlanan aktivitelerdir [5].

Bu alanda yapılan çalışmalarda, günümüzdeki çocukların geçmiş yıllara nazaran daha hantal, kilolu ve sedanter yaşam tarzını tercih ettikleri tespit edilmiştir. Ulusal Beslenme ve Sağlık Araştırması (NHANES) taramalarında çocuk ve adölesan çağındaki hareketsizliğin yaşla birlikte arttığı ve günde yaklaşık yedi saatin üzerine çıktığı kaydedilmiştir [6]. Ayrıca DEHB olan ilkokul ve ortaokul dönemindeki çocuklarda uyumsal davranış, benlik kavramı ve iletişim gibi konularda çalışmalar yapıldığı, fiziksel aktivite düzeyleri ile ilgili çalışmaların olmadığı görülmüştür [7-9].

Bu çalışmanın amacı, 8-14 yaş grubunda yer alan, DEHB olan çocukların fiziksel aktivite düzeylerinin (FAD) incelenmesi, DEHB ile FAD arasında ilişkiyi ve sağlıklı kontrol grubuna göre anlaml bir fark bulunup bulunmadığının belirlenmesi, buna yönelik önerilerin tartışılmasıdır.

\section{Materyal ve Metot \\ 2.1. Birey}

"Dikkat Eksikliği ve Hiperaktivite Bozukluğu Olan Çocukların Fiziksel Aktivite Düzeyleri” konulu tez çalışması 5 Şubat-20 Nisan 2018 tarihleri arasında Bursa/Nilüfer ilçesinde yer alan Milli Eğitim Müdürlüğü'ne bağlı ilkokul ve ortaokullarda okuyan gönüllü bireyler üzerinden gerçekleştirildi [10].

Çalışmaya dahil edilme kriterleri; çalışma grubu çocukları için DEHB tanısı almış olmak, kontrol grubu çocukları için de hiçbir sağlık problemi olmamak (a), 814 yaş aralığında olmak (b), yeterli Türkçe okumayazma bilgisine sahip olmak (c), koopere olmaktır (d). Çalışmaya dahil edilmeme kriterleri ise; fiziksel aktiviteyi kısıtlayacak ortopedik engele sahip olmak (a), mental retardasyonu bulunmak (b), dil ve zihin gelişimine engel oluşturan bir rahatsızlığı olmak (c), ailenin gönüllü olmaması (d), çalışmanın yapıldı ̆̆ı hafta fiziksel aktiviteyi engelleyecek herhangi bir rahatsızlığ bulunmaktır (e).

Çalışma, 21.11.2017 tarihinde Bezmialem Vakıf Üniversitesi Girişimsel Olmayan Klinik Araştırmalar Etik Kurulu Komitesi'nde 21/283 kararıyla onaylandı ve Helsinki Bildirgesi'ne uygun olarak yürütüldü.

Her iki grup öğrencileri ile görüşme, açıklama, gerekli veli onayının alınması ve anket uygulama işlemleri İl Milli Eğitim Müdürlüğü onayı ve eğitim kurumları rehber öğretmenleri nezaretinde yapıldı. Öğrenciler çalışmaya dahil edilmeden önce velilerine etik kurul değerlendirme standartlarında hazırlanmış olan 'Bilgilendirilmiş Gönüllü Olur Formu' okutularak imzalatıldı. Çalışma prospektif, yüz-yüze görüşme ve anket (survey) uygulama yöntemine dayalı olarak planlandi ve uygulandı.

\subsection{Yöntem}

8-14 yaş grubuna giren 80 öğrenci (39 DEHB, 41 Sağlıklı) gönüllü ve veli izinleri alınarak prospektif çalışmaya alındı. Bu çalışma bir psikiyatr tarafından DEHB tanısı konmuş öğrencilerin okul bilgileri İl Milli Eğitim Müdürlüğü izni ile Nilüfer Rehberlik ve Araştırma Merkezi'nden (RAM) alınarak gerçekleştirildi.

Çalışma ve kontrol grubunda yer alan öğrencilerin demografik, kişisel, fiziksel ve klinik bilgileri kaydedildi. Tüm bireylerin fiziksel aktivite düzeyi "Çocuklar için Fiziksel Aktivite Ölçeği (ÇFAÖ, Physical Activity Questionnare for Children (PAQ-C))" ile ölçüldü. 
Ölçeğin uygulanması çalışma grubunda 25-30 dakika kontrol grubunda yaklaşık 15 dakika sürdü. Çalışma grubundan 5, kontrol grubundan 4 öğrenci çalışmanın yapıldığ 1 hafta aktivitelerini engelleyecek rahatsızlıklara sahip olduklarından çalışma dışı bırakıldı.

\subsection{Demografik Bilgiler}

Çalıșmaya katılan her bireyin klinik, demografik ve kişisel bilgileri, hazırlanmış "Demografik Bilgi Formları" nda toplandı. Kişisel bilgi olarak; bireyin adısoyad1, demografik bilgi olarak yaş (yıl), cinsiyet, boy $(\mathrm{cm})$, kilo $(\mathrm{kg})$, vücut kitle indeksi (vücut ağırlığ $1 /$ boy2$\mathrm{kg} / \mathrm{m} 2$ ) kaydedildi. Ebeveynlere çocukların ek hastalık varlığı, kullandıkları ilaçlar, geçirilmiş operasyon varlığı, prematüre doğum olup olmadığı ve aile gelir düzeyleri sorularak kaydedildi. Ayrıca öğrencilerin beslenme durumu 3 ana başlık (Fast Food, Çikolata, Sağlıkl Besinler) altında incelendi. Tüketim sıklıklarını 1'den 5'e kadar (1 çok az, 5 çok fazla) puanlamaları istendi. Elde edilen bilgiler not edildi.

2.4.Çocuklar için Fiziksel Aktivite Ölçeği (PAQ-C)

Çalışmada Crocker ve arkadaşları tarafindan 1977 yılında geliştirilen ve geçerlilik-güvenilirlik çalışmalar yapılan "Çocuklar için Fiziksel Aktivite Ölçeği (Physical Activity Questionnare for Children [PAQ-C])" kullanıld [11]. Bu ölçek Türkçe'ye uyarlanmış olup 8-14 yaş grubu Türk çocuklarının fiziksel aktivite düzeylerinin belirlenmesinde kabul ve güvenilir bulunmuştur [12].

Ölçek son 7 gün içerisinde yapılan fiziksel aktiviteleri hatırlamaya yöneliktir ve 9 adet sorudan oluşmaktadır. Bir ilave soru olarak da ankette son 7 günde fiziksel aktivite yapılmasına engel bir olay olup olmadığ sorgulanmaktadır. Bu 9 adet soru ile çocuğun son 7 gün içinde gerçekleştirdiği fiziksel aktiviteler ve bu aktivitelerin gerçekleştirilme sıklığı sorgulanmaktadır. $\mathrm{Bu}$ ölçekte; son 7 gün içinde belirtilen aktivitelerden herhangi birini (sıçrama-atlama, kovalamaca, bisiklet, futbol, basketbol, jimnastik vb.) yapma (1), beden eğitim dersine katılma düzeyi (2), teneffüslerde genellikle hangi aktiviteyi yaptığı (3), öğle yemekleri esnasında ne tür aktivite sergilediği (4), okuldan çıktıktan sonra katıldığ aktivite sayısı (5), akşam saatlerinde yapmış olduğu aktivite sıklığı (6), hafta sonu günlerinde katıldığ aktivite sıklığı (7), geçen 7 gün içinde hangi sıklıkta yapılmış aktivitenin kendisini en iyi şekilde tanımladığ (8), ve son olarak verilen bir çizelgede spor, dans, oyun gibi fiziksel bir aktiviteyi günlere göre hangi sıklikla yaptığ 1 (9) sorgulanmaktadır.

$\mathrm{Bu}$ sorular, çoğunlukla davranışın sıklığını gösteren ancak farklı yapılarda hazırlanmış beşli seçenek şeklindedir. Birinci soruda 21 aktivite (kovalamaca, egzersiz için yürüyüş, bisiklet, futbol, basketbol gibi) yer almaktadır. Bu aktivitelerin yapıldığı sıklık durumuna (hayır yapmadım=1 puan, 1-2 kez=2 puan, 3-4 kez=3 puan, $5-6 \mathrm{kez}=4$ puan, 7 veya daha fazla $=5$ puan) göre alınan toplam puan aktivite sayısına (21) bölünerek ortalama puanı hesap edilmektedir. Mesela; birinci soruda öğrenci tüm aktiviteleri 3-4 kez yaptım olarak işaretlediğinde, 21 sayısı, aktivitelerin yapıldı ̆̆ 1 sıklık durumunu belirten 3 puan ile çarpılacak, bulunan 63 sayısı birinci soruda yer alan aktivite sayısına yani 21 'e bölünerek elde edilen rakam (3 puan) birinci sorunun ortalama puanını gösterecektir. İkinci, üçüncü, dördüncü, beşinci, altıncı, yedinci ve sekizinci soruların her birinde beş seçenek vardır; a seçeneği 1 puan, b seçeneği 2 puan, c seçeneği 3 puan, d seçeneği 4 puan, e seçeneği 5 puandir.

Dokuzuncu soru; haftanın yedi gününü gösteren bir çizelgedir. Öğrenciden, geçen haftayı düşünerek spor yapmak, dans etmek veya bir başka fiziksel aktiviteyi hangi sıklıkla yaptığını haftanın her bir günü için işaret koyarak doldurması istenmektedir. Burada hiç=1 puan, çok az $=2$ puan, orta $=3$ puan, sıklıkla $=4$ puan, çok sık $=5$ puandır. Birinci soruya benzer şekilde, dokuzuncu soruda elde edilen toplam puan gün sayısı olan 7'ye bölünerek ortalama puan hesaplanacaktır.

Böylece dokuz sorudan oluşan soru formunun maddelerine verilen cevaplara gore toplam puan elde edilecektir. PAQ-C'nin her bir maddesi için alınacak minimum puan 1 , maksimum puan 5'tir. PAQ-C'den elde edilecek minimum puan 9 , maksimum puan 45 'tir. Alınan toplam skorun madde sayısına (9'a) bölümü özet skoru verir [13].

Onuncu soru puanlanmaya dahil edilmemektedir. Öğrencinin o hafta içinde fiziksel aktivite yapmasını engelleyen hastalık, sakatlı gibi bir durum varsa o öğrenciye ait soru formunun değerlendirmeye alınmaması için oluşturulmuştur.

2.5. Verilerin Analizi

Veriler; sayı, yüzde, frekans, ortalama, standart sapma değerleri kullanılarak tanımlandı. Veri analizleri SPSS (Statistical Package for Social Science) 21.0 paket programı ile yapıldı. Verilerin normal dağılımı "Kolmogorow-Smirnov testi" ile bakıldı. Normal dağ1lımın olduğu durumlarda "Student-t testi" ve "Varyans analizi (ANOVA)" kullanıldı. Öğrencilerin beslenme şekillerini karşılaştırmak amacı ile " $\chi 2$ (Kikare) testi" kullanıld1. Analizlerde, " $p<0,05$ " istatistiksel olarak anlamlı kabul edildi.

Çalışmanın örneklem büyüklüğünü tespit etmek için korelasyon düzeyi $(\mathrm{r}=0.500), \% 80$ power ve $\% 95$ güven düzeyi ile tespit edebilmek adına her bir grup için minimum otuz vakanın çalışmaya dahil edilmesi gerektiği hesaplandi.

\section{Bulgular ve Tartışma \\ 3.1. Bulgular}

Çalışmaya 8-14 yaş arasında 26'sı kız (\%37) ve 45'i erkek (\%63) olmak üzere 71 çocuk birey alındı. Çalışma grubu için 3'ü Cavit Çağlar Ortaokulu'nda, 2'si Emir Koop İlkokulu'nda, 3'ü Hüsnü Züber İlkokulu'nda, 7'si Koç Ortaokulu'nda, 2'si Vahide Aktuğ Ortaokulu'nda, 3'ü Üçevler Şehit Faik Gökçen İlkokulu'nda, 2'si Fethiye Ortaokulu'nda, 12'si Özlüce Özel Sınav Ortaokulu'nda olmak üzere "DEHB tanısı almış" toplam 34 öğrenci; kontrol grubu için ise 13'ü Balat Özel Sınav İlkokulu'nda, 24'ü Balat Özel Sinav Ortaokulu'nda öğrenim gören "DEHB tanısı almamış" toplam 37 öğrenci gönüllü birey olarak alındı. Çalıșma grubundaki DEHB'li öğrencilerin 9’u Tip-I $(\% 26,5)$, 9’u Tip-II 
$(\% 26,5)$ ve 8 'i Tip-III $(\% 23,5)$ tanılıydı. Sekiz öğrencinin $(\% 23,5)$ DEHB tipi bilinmemekteydi.

Her iki gruptaki öğrencilerin cinsiyet dağılımına baktığımızda çalışma grubunda \%21 kı, \%79 erkek; kontrol grubunda ise $\% 51 \mathrm{k1z}, \% 49$ erkek vard1. Erkek öğrenci oranının çalışma grubunda kontrol grubuna göre daha fazla olduğu görüldü ( $\mathrm{p}=0,01$, Şekil 1).
Çalışma ve kontrol grubuna alınan tüm öğrencilerin \%10'u 8 yaş, \%23'ü 9-10 yaş, \%37'si 11-12 yaş, \%30'u 13-14 yaş arasında olduğu tespit edildi. Çalışma ve kontrol gruplarının demografik özellikleri benzer bulundu ( $>>0,05$, Tablo 1$)$.

Kiz $\square$ Erkek

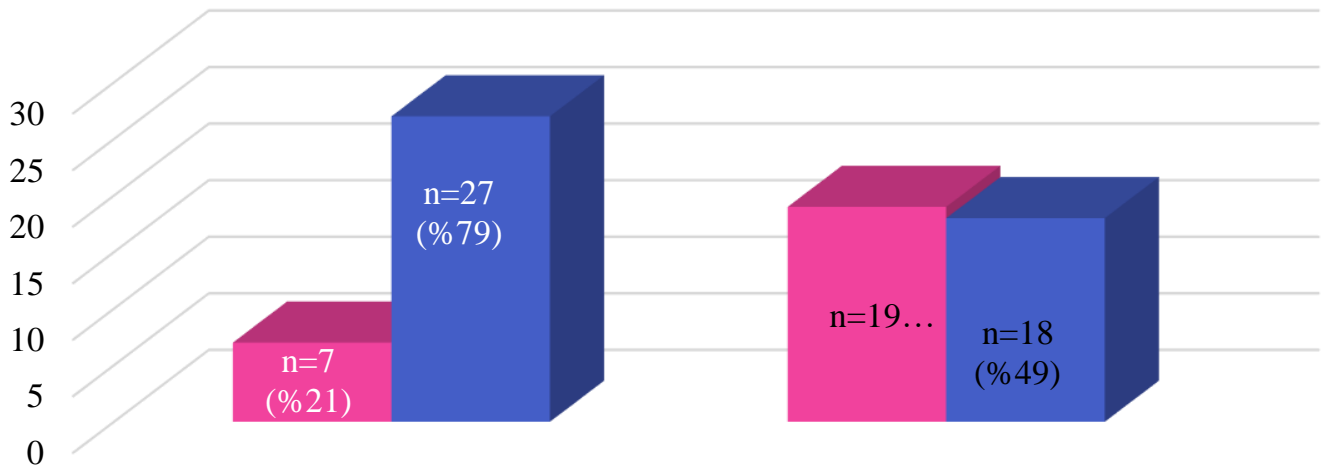

Çalışma Grubu (n=34)

Kontrol Grubu (n=37)

Şekil 1. Çalışma ve kontrol gruplarının cinsiyete göre dağılımı (n: Kişi sayısı, \%: Kişi sayısının grup içindeki yüzde dağılımı)

Tablo 1. Çalışma ve kontrol gruplarındaki öğrencilerin demografik özelliklerinin karşılaştırılması

\begin{tabular}{|c|c|c|c|c|}
\hline & $\begin{array}{l}\text { Çalışma Grubu } \\
\qquad(n=34)\end{array}$ & $\begin{array}{l}\text { Kontrol Grubu } \\
\qquad(\mathbf{n}=37)\end{array}$ & $\mathbf{t}$ & $\mathbf{P}$ \\
\hline & $\overline{\mathrm{X}} \pm \mathrm{SS}$ & $\overline{\mathrm{X}} \pm \mathrm{SS}$ & & \\
\hline Yaş (yıl) & $11,14 \pm 1,72$ & $11,51 \pm 2,09$ & $-0,802$ & 0,42 \\
\hline Boy $(\mathbf{c m})$ & $144,88 \pm 13,52$ & $145,62 \pm 13,07$ & $-0,068$ & 0,81 \\
\hline Kilo (kg) & $40,23 \pm 9,91$ & $41,45 \pm 11,96$ & $-0,467$ & 0,64 \\
\hline VKİ (kg/m²) & $18,99 \pm 3,56$ & $19,38 \pm 3,82$ & $-0,446$ & 0,65 \\
\hline
\end{tabular}

n: Kişi sayısı, x̄: Aritmetik ortalama, ss: Standart sapma, VKİ: Vücut Kitle İndeksi.

Çalışma ve kontrol grubundaki tüm öğrencilerin eğitim düzeyleri incelendiğinde, \%28'inin ilkokul düzeyinde, $\% 72$ 'sinin ise ortaokul düzeyinde eğitim görmekte oldukları anlaşıldı. Bu dağılım çalışma grubunda \%20,6 ilkokul düzeyi, \%79,4 ortaokul düzeyi şeklindeydi. Kontrol grubunda ise öğrencilerin \%35'i ilkokulda, $\% 65$ 'i ortaokulda okumaktayd.

Çalışma grubundaki öğrencilerin aile gelir düzeyleri incelendiğinde, gelir düzeylerinin \%32,35'inin yüksek, $\% 61,77$ 'sinin orta, \%5,88'inin de düşük olduğu tespit edildi. Kontrol grubundaki öğrencilerin ise aile gelir düzeyinin $\% 67,57$ 'sinin yüksek, $\% 32,43$ 'ünün orta olduğu tespit edildi.

Çalışma grubunda sadece bir öğrenci $(\% 2,94)$ prematüre doğumluydu. Altı öğrenci $(\% 17,64)$ daha önceden operasyon geçirmişti. 16 öğrenci $(\% 47,05)$ ilaç kullanmakta idi. İlaç kullanan öğrencilerin 6's1 $(\% 37,50)$ Tip-I, 5'i (31,25) Tip-II, 3'ü (18,75) Tip-III, diğer 2'sinin $(12,50)$ ise tipi bilinmemekteydi. Kontrol grubu öğrencilerinde ise hiçbirinde prematüre doğum ve ilaç kullanımı kaydedilmedi. Dört öğrenci $(\% 10,81)$ daha önceden operasyon geçirmişti.

Çalışma ve kontrol gruplarında beslenme şekli ve tüketim sıklığı incelendiğinde, her iki grupta da "sağlıklı besin"in en çok, "çikolata, bisküvi vs."nin orta, "fast food"un en az tüketilen besin olduğu tespit edildi. Çalışma ve kontrol gruplarının fast food ve çikolata, bisküvi vs. benzer olduğu ( $p>0,05)$, ancak sağlıklı besin kullanımlarının farklı olduğu görüldü ( $<<0,05$, Tablo 2). 
Tablo 2. Çalışma ve kontrol gruplarının beslenme şekillerinin karşılaştırılması

\begin{tabular}{|l|c|c|c|c|}
\hline & $\begin{array}{c}\text { Çalışma Grubu } \\
(\mathbf{n = 3 4 )}\end{array}$ & $\begin{array}{c}\text { Kontrol Grubu } \\
(\mathbf{n = 3 7 )}\end{array}$ & $\chi^{\mathbf{2}}$ & P \\
\hline Fast Food & $\overline{\mathrm{x}} \pm$ SS & $\overline{\mathrm{x}} \pm$ sS & & 0,30 \\
\hline Çikolata, Biskuvi vs. & $2,76 \pm 1,41$ & $2,51 \pm 1,09$ & 4,876 & 0,46 \\
\hline Sağlıkıı Besin & $3,47 \pm 1,35$ & $3,48 \pm 1,09$ & 3,572 & 0,03 \\
\hline
\end{tabular}

n: Kişi sayısı, $\overline{\mathrm{x}}$ : Aritmetik ortalama, ss : Standart sapma, $\chi^{2}$ : Ki-kare.

Çalışmadaki Tip-I, Tip-II ve Tip-III gruplarının fast food, çikolata, bisküvi ve sağlıklı besin tüketiminin benzer düzeyde olduğu saptandı ( $\mathrm{p}>0,05)$. "Fast food" ve "Çikolata, bisküvi vs.” tüketiminin en fazla Tip-III grubundaki çocuklarda olduğu görüldü $(3,75 \mathrm{p}$, Tablo 3$)$.

Tablo 3. Çalışma grubundaki öğrencilerin DEHB tiplerine göre beslenme şekillerinin karşılaştırılması

\begin{tabular}{|l|c|c|c|c|c|}
\hline & $\begin{array}{c}\text { Tip-I } \\
(\mathbf{n = 9})\end{array}$ & $\begin{array}{c}\text { Tip-II } \\
(\mathbf{n = 9})\end{array}$ & $\begin{array}{c}\text { Tip-III } \\
(\mathbf{n}=\mathbf{8})\end{array}$ & $\chi^{\mathbf{2}}$ & P \\
\hline Fast Food & $\overline{\mathrm{x}} \pm \mathrm{SS}$ & $\overline{\mathrm{X}} \pm \mathrm{sS}$ & $\overline{\mathrm{x}} \pm \mathrm{SS}$ & & 0,26 \\
\hline Çikolata, Biskuvi vs. & $2,55 \pm 1,50$ & $2,44 \pm 1,33$ & $3,75 \pm 1,28$ & 10,027 & 0,69 \\
\hline Sağlıklı Besin & $3,33 \pm 1,32$ & $3,11 \pm 1,45$ & $3,75 \pm 1,48$ & 5,620 & 0,68 \\
\hline
\end{tabular}

n: Kişi sayısı, $\overline{\mathrm{x}}$ : Aritmetik ortalama, ss : Standart sapma, $\chi^{2}$ : Ki-kare.

Çalışma grubunda aktivite ölçeği toplam ortalama skoru 33,28'di. Çalışma grubundaki öğrencilerin maksimum performans düzeyi \%73,95'ti. Sorular arasında en düşük ortalama skor 1. soruya $(2,12)$, en yüksek ortalama skor ise 2. soruya aitti $(4,64)$. Kontrol grubunda aktivite ölçeği toplam ortalama skoru $27,09^{\prime}$ du. Kontrol grubundaki öğrencilerin maksimum performans düzeyi \%60,20’ydi.
Sorular arasında en düşük ortalama skor 1. soruya $(2,13)$, en yüksek ortalama skor ise 2 . soruya aitti $(4,29)$. Çalışma ve kontrol grubu karşılaştırıldığında çalışma grubundaki öğrencilerin 3., 5., 7., 8., ve 9. soru skorlarının kontrol grubuna göre daha yüksek olduğu görüldü ( $<<0,05$, Tablo 4).

Tablo 4. Çalışma ve kontrol gruplarının PAQ-C soru skorlarının karşılaştırılması

\begin{tabular}{|c|c|c|c|c|}
\hline & $\begin{array}{l}\text { Çalışma Grubu } \\
\qquad(n=34)\end{array}$ & $\begin{array}{c}\text { Kontrol Grubu } \\
\qquad(\mathbf{n}=37)\end{array}$ & \multirow[t]{2}{*}{$\mathbf{t}$} & \multirow[t]{2}{*}{$\mathbf{P}$} \\
\hline & $\overline{\mathrm{X}} \pm \mathrm{SS}$ & $\overline{\mathrm{X}} \pm \mathrm{SS}$ & & \\
\hline Boş zaman aktiviteleri & $2,12 \pm 0,43$ & $2,13 \pm 0,70$ & $-0,043$ & 0,97 \\
\hline Beden Eğitimi dersi aktifliği & $4,64 \pm 0,81$ & $4,29 \pm 0,81$ & 1,813 & 0,07 \\
\hline Teneffüsteki aktifliği & $4,17 \pm 0,94$ & $2,59 \pm 1,50$ & 5,277 & 0,01 \\
\hline Öğle arası aktifliği & $3,61 \pm 1,44$ & $3,05 \pm 1,75$ & 1,477 & 0,14 \\
\hline Okul sonrası aktiviteleri & $3,76 \pm 1,28$ & $2,94 \pm 1,22$ & 2,755 & 0,01 \\
\hline Akşam aktiviteleri & $3,41 \pm 1,40$ & $2,89 \pm 1,20$ & 1,689 & 0,10 \\
\hline Hafta sonu aktiviteleri & $4,08 \pm 1,16$ & $2,94 \pm 1,25$ & 3,982 & 0,01 \\
\hline Son 7 günün yorumu & $3,76 \pm 1,07$ & $3,00 \pm 1,20$ & 2,817 & 0,01 \\
\hline $\begin{array}{l}\text { Haftanın günlerine göre aktivite } \\
\text { yorumu }\end{array}$ & $3,76 \pm 0,67$ & $3,28 \pm 0,95$ & 2,446 & 0,02 \\
\hline
\end{tabular}

$\mathrm{n}:$ Kişi Sayısı, $\overline{\mathrm{x}}$ : Aritmetik ortalama, ss : Standart sapma. 
Çalışma ve kontrol grubu öğrencilerinin PAQ-C özet skorları karşılaştırıldığında çalışma grubunun özet skoru kontrol grubuna göre istatistiksel olarak daha yüksek bulundu $(\mathrm{p}=0,00$, Şekil 2).

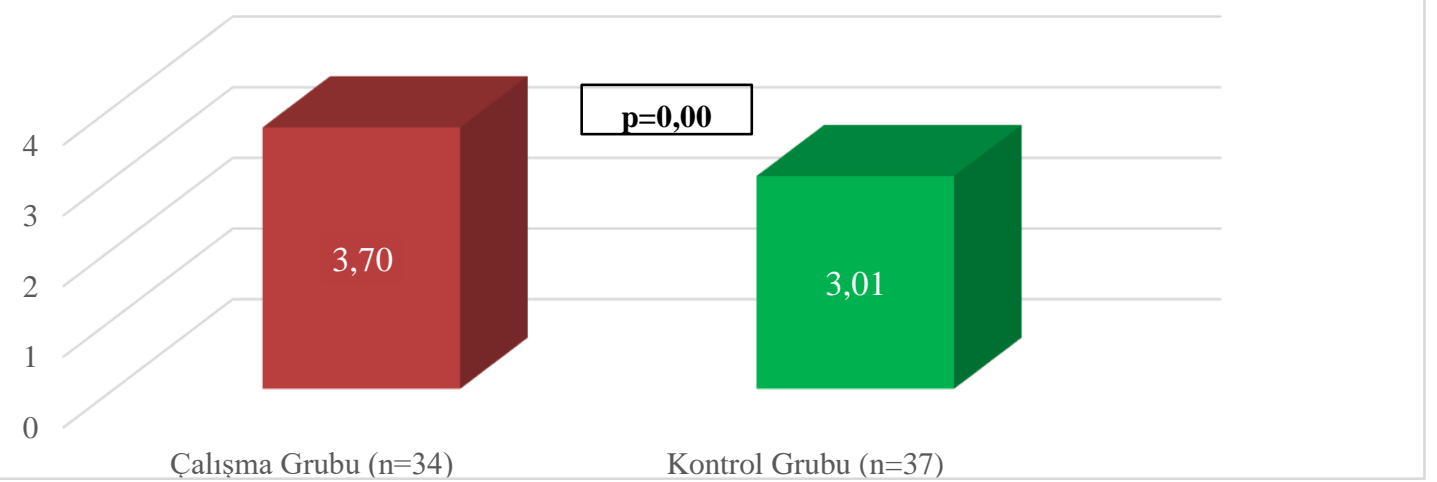

Şekil 2. Çalışma ve kontrol gruplarının PAQ-C özet skorlarının karşılaştırılması

Çalışma grubu öğrencilerinin cinsiyete göre PAQ-C özet skorları karşılaştırıldığında istatistiksel açıdan benzer bulundu ( $p>0,05)$. Kontrol grubu öğrencilerinin cinsiyete göre PAQ-C özet skorları karşılaştırıldığında ise erkeklerin özet skoru kızlara göre istatistiksel olarak daha yüksek bulundu ( $\mathrm{p}<0,05$, Tablo 5).

Tablo 5. Çalışma ve kontrol gruplarındaki öğrencilerin cinsiyete göre PAQ-C özet skorlarının karşılaştırılması

\begin{tabular}{|c|c|c|c|c|}
\hline & \multirow[t]{2}{*}{ Cinsiyet } & PAQ-C özet skoru & \multirow[t]{2}{*}{$\mathbf{t}$} & \multirow[t]{2}{*}{$\mathbf{P}$} \\
\hline & & $\overline{\mathbf{x}} \pm \mathbf{S S}$ & & \\
\hline \multirow[t]{2}{*}{ Çalışma Grubu } & $\mathrm{K}_{1 \mathrm{Z}}(\mathrm{n}=7)$ & $3,58 \pm 0,62$ & \multirow[t]{2}{*}{0,612} & \multirow[t]{2}{*}{0,54} \\
\hline & Erkek $(n=27)$ & $3,73 \pm 0,57$ & & \\
\hline \multirow[t]{2}{*}{ Kontrol Grubu } & $\mathrm{K} 1 \mathrm{z}(\mathrm{n}=19)$ & $2,48 \pm 0,50$ & \multirow[t]{2}{*}{5,231} & \multirow[t]{2}{*}{0,01} \\
\hline & Erkek (n=18) & $3,57 \pm 0,74$ & & \\
\hline
\end{tabular}

$\mathrm{n}$ : Kişi Sayısı, $\overline{\mathrm{x}}$ : Aritmetik ortalama, ss : Standart sapma.

Çalışma grubundaki öğrencilerin DEHB tiplerine göre PAQ-C soru skorlarının karşılaştırılmasında istatistiksel olarak anlamlı bir fark yoktu $(\mathrm{p}>0,05)$. Soruların hepsinde en yüksek skorlar Tip-II'ye aitti. "Beden eğitimi dersindeki aktifliği”’ sorgulayan skor tüm tiplerde en yüksek değerdi (Tablo 6).

Tablo 6. Çalışma grubundaki öğrencilerin DEHB tiplerine göre PAQ-C soru skorlarının karşılaştırılması

\begin{tabular}{|c|c|c|c|c|}
\hline & $\begin{array}{l}\text { Tip-I } \\
(\mathbf{n}=9) \\
\bar{x} \pm s S\end{array}$ & $\begin{array}{l}\text { Tip-II } \\
(\mathbf{n}=9) \\
\bar{x} \pm \text { ss }\end{array}$ & $\begin{array}{c}\text { Tip-III } \\
(\mathbf{n}=8) \\
\bar{x} \pm S S\end{array}$ & $\mathbf{P}$ \\
\hline & & & & \\
\hline Boş zaman aktiviteleri & $2,17 \pm 0,42$ & $2,27 \pm 0,40$ & $2,11 \pm 0,59$ & 0,76 \\
\hline Beden Eğitimi dersi aktifliği & $4,44 \pm 1,33$ & $5,00 \pm 0,00$ & $4,75 \pm 0,46$ & 0,35 \\
\hline Teneffüsteki aktifliği & $3,77 \pm 1,20$ & $4,66 \pm 0,50$ & $4,12 \pm 0,99$ & 0,14 \\
\hline Öğle arası aktifliği & $2,11 \pm 1,36$ & $4,44 \pm 0,88$ & $4,37 \pm 0,74$ & 0,98 \\
\hline Okul sonrası aktiviteleri & $2,88 \pm 1,05$ & $4,77 \pm 0,66$ & $3,62 \pm 1,50$ & 0,36 \\
\hline Akşam aktiviteleri & $2,44 \pm 1,50$ & $4,33 \pm 1,11$ & $3,37 \pm 1,41$ & 0,32 \\
\hline Hafta sonu aktiviteleri & $3,22 \pm 0,97$ & $4,44 \pm 1,33$ & $4,37 \pm 1,18$ & 0,09 \\
\hline Son 7 günün yorumu & $3,33 \pm 1,32$ & $4,33 \pm 1,00$ & $3,75 \pm 0,88$ & 0,16 \\
\hline $\begin{array}{l}\text { Haftanın günlerine göre aktivite } \\
\text { yorumu }\end{array}$ & $3,26 \pm 0,36$ & $4,33 \pm 0,69$ & $3,83 \pm 0,52$ & 0,16 \\
\hline
\end{tabular}

$\mathrm{n}$ : Kişi Sayısı, $\overline{\mathrm{x}}$ : Aritmetik ortalama, ss : Standart sapma. 
DEHB'li öğrencilerde tiplere göre PAQ-C toplam ortalama skorları incelendiğinde tüm sorular için toplam skor Tip-I'de 27,62, Tip-II'de 38,57, Tip-III'te 34,29'du. DEHB tipi belirsiz öğrencilerin toplam fiziksel aktivite skoru 32,78 ' di.
Çalışma grubundaki öğrencilerin DEHB tipleri ile PAQC özet skorları karşılaştırıldığında Tip-II grubunun özet skoru diğer gruplara göre istatistiksel olarak yüksek bulundu $(\mathrm{p}=0,00$, Şekil 3).

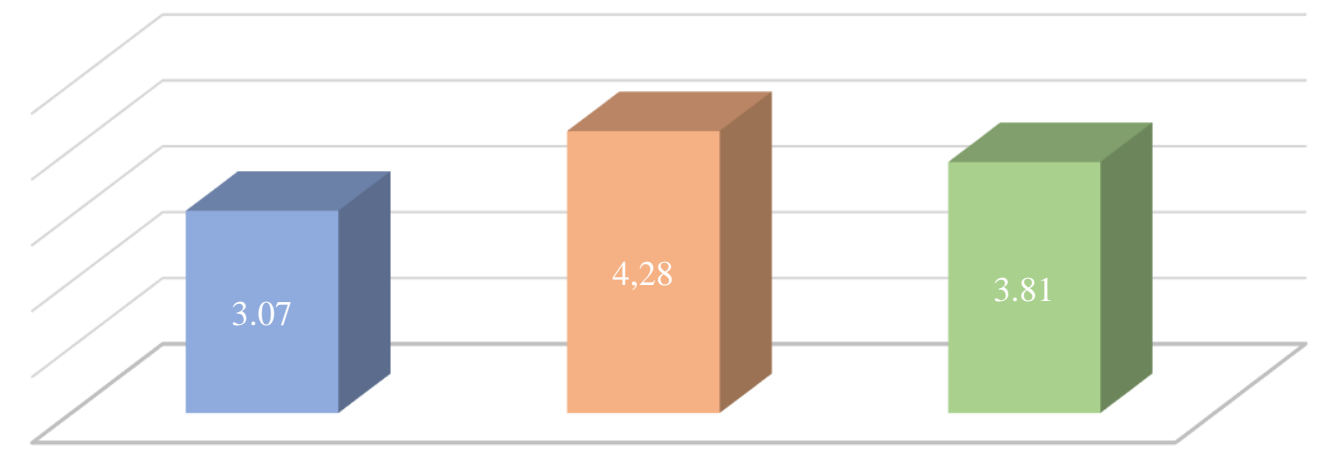

$\square$ Tip I $\square$ Tip II $\square$ Tip III $\mathrm{p}=0,00$

Şekil 3. Çalışma grubunun DEHB tiplerine göre PAQ-C özet skorlarının karşılaştırılması

Tablo 7. Çalışma grubundaki öğrencilerin ilaç kullanma durumlarına göre demografik özelliklerinin karşılaştırılması

\begin{tabular}{|c|c|c|c|c|}
\hline & $\begin{array}{c}\text { İlaç kullananlar (n=16) } \\
\qquad \overline{\mathrm{X}} \pm \mathrm{SS}\end{array}$ & $\begin{array}{c}\text { İlaç kullanmayanlar } \\
\qquad \begin{array}{c}(\mathbf{n}=\mathbf{1 8}) \\
\overline{\mathrm{X}} \pm \mathrm{SS}\end{array}\end{array}$ & $\mathbf{t}$ & $\mathbf{P}$ \\
\hline Yaş (yıl) & $11,12 \pm 1,70$ & $11,16 \pm 1,79$ & 0,069 & 0,94 \\
\hline Boy (cm) & $146,43 \pm 12,32$ & $144,05 \pm 11,18$ & $-0,591$ & 0,55 \\
\hline Kilo (kg) & $39,62 \pm 9,54$ & $40,77 \pm 10,47$ & 0,334 & 0,74 \\
\hline VKİ $\left(\mathrm{kg} / \mathrm{m}^{2}\right)$ & $18,51 \pm 3,34$ & $19,41 \pm 3,78$ & 0,735 & 0,46 \\
\hline
\end{tabular}

$\mathrm{n}$ : Kişi Sayısı, $\overline{\mathrm{x}}$ : Aritmetik ortalama, ss : Standart sapma.

Tablo 8. Çalışma grubundaki öğrencilerin ilaç kullanma durumlarına göre PAQ-C özet skorlarının karşılaştırılması

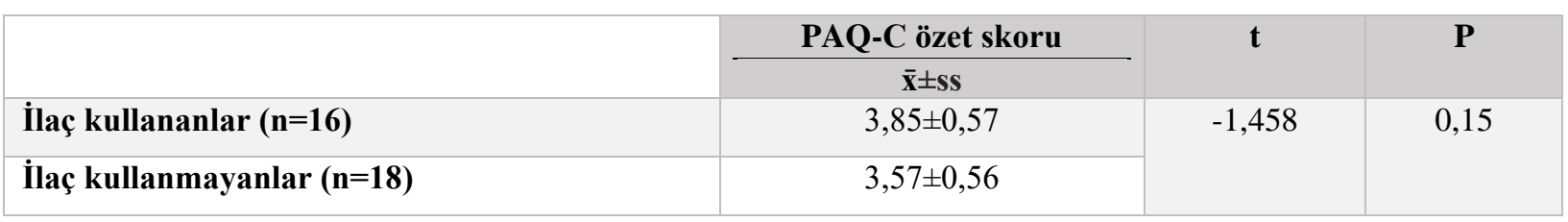

$\mathrm{n}$ : Kişi Sayısı, $\overline{\mathrm{x}}$ : Aritmetik ortalama, ss : Standart sapma.

\subsection{Tartışma}

Bu çalışmada, yaşları 8-14 arasında olan DEHB tanılı 34, DEHB tanılı olmayan 37 öğrenciye "Çocuklar için Fiziksel Aktivite Ölçeği” uygulanmış, DEHB tanılı çocukların fiziksel aktivite düzeylerinin sağlıklılara göre daha yüksek olduğu saptanmıştır.

Türkiye'de yapılan bir çalışmada okul çağı çocuklarında DEHB'li kız/erkek oranı 1/4 olarak verilmiştir (14). Öner ve arkadaşları da DEHB'li çocuklarda bu bozukluğun erkek çocuklarda daha fazla görüldüğünü saptamışlardır [15]. Bizim çalışmada 34 DEHB'li öğrencinin cinsiyet dağılımına baktığımızda çocukların 7'si kız ve 27'si (\%79) erkekti. DEHB'li öğrencilerimizin kı/erkek oranının 1/4 olması literatürü desteklemektedir.
Görmez ve Örengül, Çocuk ve Ergen Psikiyatrisi Polikliniği'ne başvuran 6-18 yaş arasındaki 360 DEHB'li çocuk ve ergenle yaptığ çalışmada, deneklerin \%54'ünün 2 bin TL ve altında, \%46'sının 2 bin TL üzeri aile gelir düzeyine sahip olduğunu saptamışlardır [16]. Bizim çalışmada DEHB'li çocuk ailelerinin \%62'sinin 2-4 bin TL arasında, \%32'sinin 4 bin TL üzerinde aylık gelire sahip oldukları; kontrol grubu çocuk ailelerinin ise $\% 68$ 'inin 4 bin TL üzerinde, \%32'sinin $2-4$ bin TL arasında aylık gelire sahip oldukları tespit edildi. Kontrol grubunda geliri 2.000 TL'nin altında olan aile yoktu. Bu durumun, öğrencilerin özel okulda okuyor olmalarından kaynaklandığg düşünüldü.

DEHB semptomları obezite ve fiziksel inaktivite için bir risk faktörüdür. Literatürde fiziksel aktivitenin olumlu 
etkilerine rağmen DEHB tanılı çocukların ve adölesanların fiziksel aktiviteye katılımlarının az olduğu ve sedanter olarak geçirdikleri sürenin daha fazla olduğu çalışmalarla gösterilmiştir [17].

Lin ve arkadaşları DEHB'li çocuklarda objektif ölçüm (ActiGraph GT1M) ile fiziksel aktiviteyi inceleyip sağlıklı çocuklarla karşılaştırdıkları çalışmada [18], DEHB'li çocukların daha yüksek fiziksel aktiviteye sahip olduğunu saptamıştır. Farklı yöntemlerle fiziksel aktiviteyi değerlendirmiş olmamıza rağmen bizim de DEHB'li grubumuzun daha yüksek fiziksel aktivite düzeyine sahip olması bu literatürü desteklemektedir. Keza Kim ve arkadaşları DEHB'li çocukların, ilaç kullanımı ve cinsiyetinden bağımsız olarak, DEHB'li olmayanlara kıyasla, şiddetli fiziksel aktiviteye ve organize sporlara katılma olasılıklarının daha az olduğunu saptamışlardır [19]. Bu durum DEHB tanılı çocuklardaki adrenerjik/ noradrenerjik disfonksiyon ile motivasyon, dikkat ve motor kontrol eksikliği gibi davranışsal semptomlar nedeniyle olabilir. Zira bu çocukların kaba motor performans ve fiziksel fitness düzeyleri düşüktür. Ayrıca motor performansta da gecikme görülebilmektedir [19,20].

Khalife ve arkadaşları fiziksel inaktivite ve aşırı yeme davranışını incelemiş, çocukluk çağında görülen DEHB semptomlarının adölesan dönemde görülen obezite ile ilişkili olduğunu ve fiziksel aktivitedeki azalmanın dikkat eksikliğinin bir göstergesi olduğunu bulmuşlardır [17]. Başka bir çalışmada da çocukluk çağındaki DEHB ve davranış bozukluğu semptomları adölesan dönemdeki fiziksel inaktivite ile ilişkilendirilmiş, davranış bozukluğu ve obeziteyi tedavi etmek için fiziksel aktivitenin yararlı olabileceği belirtilmiştir [21].

Köprülü'nün tez çalışmasında, 11-17 grubu çocuklarda fiziksel aktivite düzeyleri incelenmiş ve DEHB'li hastaların adım sayılarının sağlıklılara göre daha düşük olduğu saptanmıştır [22]. Bizim çalışmamızda yukarıdaki literatürlerden farklı olarak DEHB'li çocuklarımızın fiziksel aktivite düzeyleri sağlıklı çocuklara göre daha yüksek bulunmuştur. Bunun nedeni fiziksel aktiviteyi yukarıdaki literatürden farklı yöntemlerle değerlendirmiş olmamdan ve vakalarımızın DEHB şiddet düzeylerinin düşük olmasından kaynaklanmış olabilir. Çalışmamızda DEHB şiddeti değerlendirilmediği için kesin veriler verilememiştir. $\mathrm{Bu}$ durumda DEHB şiddetinin de araştırıldığı ileri çalışmalara ihtiyaç olduğu açıktır.

DEHB tedavisinde kullanılan psikostimülanlar, dopaminerjik ve noradrenaljik sisteme etki eder. $\mathrm{Bu}$ da frontal korteks fonksiyonunun düzelmesine ve DEHB semptomlarının iyileşmesine neden olur. Kullanılan ilaçların ilgili sistemleri etkileyerek semptomları düzeltmesi ve anoreksijenik yan etkisi DEHB ve obezite arasındaki ilişkiyi azaltmaktadır (21). Schwartz ve arkadaşları 3-18 yaş arasındaki 16.820 çocuk ve adölesanda DEHB tipi, ilaç kullanımı ve VKİ ile ilişkisini incelemiş, DEHB'li ve ilaç kullanmayan çocukların ilaç kullananlara göre VKI'‘nin daha yüksek olduğunu saptamışlardır [23].
Kim ve arkadaşları 6-17 grubu çocuk ve adölesanlarda DEHB'li ve ilaç kullanmayan erkeklerin $\% 42$ oranında daha fazla obez olma riski taşıdı $\breve{g}_{1}$; kızlarda ise bu oranın \%85 ve üzerinde olduğunu bulmuşlardır (19). Başka bir araştırmada DEHB'li ve ilaç kullanmayan çocukların başlangıçta normalden daha yüksek VKİye sahip oldukları, ilaç kullanımının boy ve kilo artışında azalmaya neden olduğu ve bunun ilaçlarının anoreksijenik etkisinden kaynaklandığı belirtilmiştir [24]. Aynı araştırmada 8-15 yaş grubunda obezite incelenmiş ve DEHB'li ilaç kullanan erkeklerin sağlıklı kontrollere göre obez olma olasılığının düşük olduğu, DEHB'li ilaç kullanmayan kızların sağlıklı kontrollere göre obez olma olasılığının 1.54 kat daha fazla olduğu saptanmıştır. Cortese ve arkadaşları da birçok çalışmayı içeren meta-analizinde çocuklarda $\% 40$, yetişkinlerde \%70 risk şeklinde obezite ile DEHB arasında anlamlı ilişki bulunduğunu kaydetmişlerdir [25].

Bizim çalışmada ise ilaç kullanan ve kullanmayan öğrencilerin VKI'lerinin benzer ve normal değerlerde (\%50 persantil) olduğu saptandı. Yukarıdaki literatürlerden farklı olarak ilaç kullanmayan grupta obezite görülmedi. Bu çocuklarda ileriki yaşlarda ilaç kullanmamaya bağlı olarak obezite oluşma riski daha belirgin hale gelebilir. Şüphesiz çocukların obezite açısından uzun süreli takiplerinin yapılması gerekmektedir.

Çocuklarda gelişimi etkileyen önemli unsurlardan biri beslenmedir. Çocukluk ve adölesan döneminde kazandırılan sağlıklı beslenme davranışı, çocukların büyüdüklerinde bu davranışı sürdürebilme yetisini arttırmaktadır. Nitekim Bilaç ve arkadaşları da DEHB tanılı çocuk ve ergenlerin yeme tutumları ve uyku paternlerini incelemiş, deneklerde uyku ve yeme sorunlarının sağlıklı gruba göre daha yüksek olduğunu belirtmişlerdir (26). Bizim çalışmamızda DEHB'li ve kontrol grubu çocukları sağlıklı beslenmeyi 3-5 bandında tercih etmişlerdir. Cortese ve arkadaşlarının çalışmasından (25) farklı olarak DEHB'li grubumuzun sağlıklı beslenme tercihi, toplumumuzdaki aile kontrolünden kaynaklanıyor olabilir. Çalışma ve kontrol grubumuzdaki çocukların çikolata tüketim sıklıklarının genellikle 3-5 arasında değişiyor olması okul saatleri içerisinde aile kontrolünün ortadan kalkması ve bu tür besinlere erişimin kolaylaşması nedeniyle olabilir.

Çalışmada kullandığım PAQ-C anketinin sorularına verilen yanıtlar incelendiğinde,

Her iki grupta anketin 1. Soru skorların düşüklüğü aile gelir düzeylerinin kıısmen düşük olamsından kaynaklanmıştır (a). Her iki grupta en yüksek skorun 2. soruya verilmesi öğrencilerin fiziksel aktivite bakımından beden eğitimi derslerini sevdiklerini göstermektedir (b). 3. soruda çalışma grubu skorunun daha yüksek olması, ders süresince oturmaktan sıkılan DEHB'li öğrencilerin teneffüs vakitlerinde biriken potansiyel enerjilerini boşaltma ihtiyacına işaret etmektedir (c). DEHB'li çocukların 5. ve 7. sorularda sorgulanan sportif etkinliklere fazlaca katılmalarının nedeni ailelerin fiziksel aktivitenin semptomlar üzerindeki pozitif etkisinin farkında olduklarını ve 
çocukların bilinçli katılımını sağladıklarını göstermektedir (d). 8. ve 9. soru skorları DEHB'li çocukların hafta boyunca akranlarına nazaran daha fazla aktivite yaptıklarını göstermiştir (e). Nitekim Cook ve arkadaşları da öğrenme güçlüğü ve DEHB olan çocuklardaki fiziksel aktiviteyi değerlendirdiği çalışmada çocukların yaklaşık \% 74'ünün haftada üç veya daha fazla gün şiddetli fiziksel aktivite ile zaman geçirdiklerini saptamışlardır [27].

$\mathrm{Bu}$ çalışma DEHB tiplerine göre değerlendirildiğinde, Tip-II çocuklarının koşma ve oynama gibi fiziksel etkinliklerden diğer tiplere göre daha fazla haz duyduğu saptandı. Tüm sorularda en yüksek skor bu grupta görüldü. PAQ-C sorularında en düşük skor Tip-I grubuna aitti. Bu durum bu tipin karakteristiği olan "günlük iş ve ödevlerini önemsemeyen, detaylara dikkat etmeyen, hatalar yapan, içine kapanık, pasif, öz güveni zayıf" gibi özellikler ile örtüşmektedir.

Çalışmanın en önemli limitasyonları; fiziksel aktivite düzeylerinin tek ölçekle değerlendirilmiş olması, bilgilerin çocukların ifadelerine dayalı olarak doldurulması ve hastalık tiplerine göre vakalarımızı ayırdığımızda hasta sayımızın yetersiz olmasıdır.

Sonuç olarak bu çocukların fiziksel aktiviye teşvik edilmesi ve semptomlarına göre uygun fiziksel aktivite programlarının düzenlenmesi gerekmektedir. Fiziksel aktivitenin çocukların davranışlarını ve kognitif performanslarını pozitif yönde etkilemesi DEHB'nin ilaç tedavisine destek olabilir. İlave olarak düzenli yapılan fiziksel aktivite obeziteyi olumlu yönde etkileyebilir. Diğer yandan öğretmen ve ebeveynlerin hastalık, semptomlar ve uygulanmasi gereken tedaviler hakkında bilgilendirilmesi çocukların daha dikkatli bir şekilde kontrol edilmesine, ailelerin daha doğru yaklaşımlar içerisinde olmalarına yardımcı olabilir. Aile ve çocuğun yaşam şartlarını bu duruma göre ayarlaması hem çocuk hem ailenin yaşam kalitesini arttırabilir.

\section{Sonuç}

1. DEHB'li kız/erkek oranı yaklaşık 1/4 iken, kontrol grubunda neredeyse $1 / 1$ bulundu.

2. DEHB'li vakaların sağlıklı gruba göre boy, kilo ve vücut kitle indeksleri normal sınırlar içinde idi (\%50 persantil).

3. DEHB'li öğrenciler sağlıklı öğrencilerden daha fazla sağlıklı besin tükettiler $(\mathrm{p}=0,03)$.

4. DEHB'li öğrencilerin teneffüslerdeki fiziksel aktivite düzeyi sağlıklı öğrencilere göre daha yüksek bulundu.

5. DEHB'li öğrencilerin okuldan sonraki günlük boş zamanları ve hafta sonlarında fiziksel aktivite düzeyi, sağlıklı öğrencilerinkinden istatistiksel olarak anlamlı derecede yüksekti.

6. Keza DEHB'li öğrencilerin bir haftalık fiziksel aktivite düzeyi, sağlıklı öğrencilerinkinden anlamlı derecede yüksek çıktı.

7. DEHB'li öğrencilerin PAQ-C özet skoru, sağlıklı öğrencilerin özet skorundan anlamlı derecede yüksek bulundu $(\mathrm{p}<0,05)$.
8. Tip-I, Tip-II ve Tip-III öğrencilerinin PAQ-C özet skorları istatistiksel bakımdan değerlendirildiğinde farklı olduğu tespit edildi $(p=0,00)$. Fiziksel aktivitenin en düşük olduğu grup DEHB Tip-I, en yüksek olduğu grup ise DEHB Tip-II tanılı öğrenciler oldu.

\section{Referanslar}

1. McCracken, J.T, Attention Deficit Hyperactivity Disorder, In: BJ Sadock, VA Sadock (Eds.), Comprehensive Textbook Psychiatry, 2000, (7th ed.), 2679-2688, Philadelphia, USA: Lippincott Williams and Wilkins.

2. Ercan, E.S, Kandulu, R, Uslu, E, Ardic, U.A, Yazici, KU, Basay, B.K, et al., Prevalence and diagnostic stability of ADHD and ODD in Turkish children: a 4-year longitudinal study, Child and Adolescent Psychiatry and Mental Health, 2013, 7(1), 1-30.

3. American Psychiatric Association, Diagnostic and Statistical Manual of Mental Disorders (DSM-V), (5th ed.), 2013, Washington, USA.

4. Ercan, E.S, Aydın, C, Dikkat Eksikliği Hiperaktivite Bozukluğu Özellikleri, Tedavisi, Çocuklarda ve Erişkinlerde Belirtileri, İçinde: ES Ercan (ed.) Dikkat Eksikliği Hiperaktivite Bozukluğu, (3. Baskı), 2000, İstanbul, Gendaş.

5. Bek, N, Fiziksel Aktivite ve Sağlı̆̆ımız, 2008, Ankara, Klasmat Matbaacilık.

6. Ergül, Ş, Kaklım, A, Önemli bir kronik hastalık: çocukluk ve ergenlik döneminde obezite, , 2011, 10(2), 223-230.

7. Kanay, A, Dikkat Eksikliği ve Hiperaktivite Bozukluğu olan 9-13 yaş grubu ilköğretim öğrencilerinin uyumsal davranışları, benlik kavramı ve akademik başarıları arasındaki ilişkiler, (Uzmanlık tezi), 2006, Dokuz Eylül Üniversitesi, Tıp Fakültesi, İzmir

8. Sergün Türe, F, Dikkat Eksikliği ve Hiperaktivite Bozukluğu olan çocukların (8-12 yaş) değişik anne tutumlarına göre benlik saygı düzeylerinin incelenmesi, (Yüksek Lisans Tezi), 2010, Maltepe Üniversitesi, Sosyal Bilimler Enstitüsü, İstanbul.

9. Hegerl, U, Himmerich, H, ADHD and Bipolar Disorder: Common Causes Common Cure? Current Opinion in Psychiatry, 2010, 6(1), 31-38.

10. Karadağ, M, Dikkat Eksikliği ve Hiperaktivite Bozukluğu Olan Cocukların Fiziksel Aktivite Düzeyleri (Yüksek Lisans Tezi), 2019, Bezmialem Vakıf Üniversitesi, Sağlık Bilimleri Enstitüsü, İstanbul.

11. Crocker, P.R, Bailey, D.A, Faulkner, R.A, Kowalski, K.C, McGrath, $\mathrm{R}$, Measuring general levels of physical activity: preliminary evidence for the Physical Activity Questionnaire for Older Children, Medicine and Science in Sports and Exercise, 1997, 29(10), 13441349

12. Sert, Z.E, Temel, A.B, İlköğretim öğrencileri için fiziksel aktivite soru formunun Türk toplumuna uyarlanması: geçerlilik ve güvenilirlik çalışması, Dokuz Eylül Üniversitesi Hemşirelik Fakültesi Elektronik Dergisi, 2014, 7(2), 109-114.

13. Janz, K.F, Lutuchy, E.M, Wenthe, P, Levy, S.M, Measuring activity in children and adolescents using self-report: PAQ-C and PAQ-A, Medicine And Science In Sports And Exercise, 2008, 40(4), 767-772.

14. Semerci, Z.B, Turgay, A, Bebeklikten Erişkinliğe Dikkat Eksikliği Hiperaktivite Bozukluğu (5. Basım), 2011, İstanbul, Alfa Basım Yayım Dağıtım.

15. Öner, P, Öner, Ö, Aysev, A, Dikkat Eksikliği ve Hiperaktivite Bozukluğu, Sürekli Tip Eğitimi Dergisi, 2003, 12(3), 97-99.

16. Görmez, V, Örengül, A..C, DEHB'li çocuk ve ergenlerin elektronik medya kullanımı açısından değerlendirilmesi, Anadolu Psikiyatri Dergisi, 2017, 18(5), 495-502.

17. Khalife, N, Kantomaa, M, Glover, V, Tammelin, T, Laitinen, J, Ebeling, H, Rodriguez, A, Childhood AttentionDeficit/Hyperactivity Disorder symptoms are risk factors for obesity and physical inactivity in adolescence, Journal of the American Academy of Child and Adolescent Psychiatry, 2014, 53(4), 425-436. 
18. Lin, C.Y, Yang, A.L, Su, C.T, Objective measurement of weekly physical activity and sensory modulation problems in children with Attention Deficit Hyperactivity Disorder, Research in Developmental Disabilities, 2013, 34(10), 3477-3486.

19. Kim, J, Mutyala, B, Agiovlasitis, S, Fernhall, B, Health behaviors and obesity among US children with Attention Deficit Hyperactivity Disorder by gender and medication use, Preventive Medicine, 2011, 52(3-4), 218-222.

20. Gapin, J.I, Labban, J.D, Etnier, J.L, The effects of physical activity on Attention Deficit Hyperactivity Disorder symptoms: The evidence, Preventive Medicine, 2011, 52, 70-74.

21. Quesada, D, Ahmed, N.U, Fennie, K.P, Gollub, E.L, Ibrahimou, B A review: Associations between attention-deficit/hyperactivity disorder, physical activity, medication use, eating behaviors and obesity in children and adolescents, Archives of Psychiatric Nursing, 2018, 32(3), 495-504.

22. Köprülü, Ö, Ekran bağımlılığı olan çocuklarda insülin duyarlılığının değerlendirilmesi. (Uzmanlık Tezi), 2014, Ege Üniversitesi, Tıp Fakültesi, İzmir

23. Schwartz, B.S, Bailey-Davis, L, Bandeen-Roche, K, Pollak, J, Hirsch, A.G, Nau, C, Glass, T.A, Attention Deficit Disorder, stimulant use, and childhood body mass index trajectory, Pediatrics, 2014, 133(4), 668-676.

24. Byrd, H.C, Curtin, C, Anderson, S.E, Attention-Deficit/Hyperactivity Disorder and obesity in US males and females, age 8-15 years: National health and nutrition examination survey 2001-2004, Pediatric Obesity, 2013, 8(6), 445-453.

25. Cortese, S, Moreira-Maia, C, St. Fleur, D, Morcillo-Peñalver, C, Rohde, LA, Faraone, S.V, Association between ADHD and obesity: A systematic review and metaanalysis, American Journal of Psychiatry, 2016, 173(1), 34-43.

26. Bilaç, Ö, Canol, T, Kavurma, C, Işıldar, Y, Yalın Sapmaz, Ş, Şentürk Pilan, B, Çatuk, E, Uzunoğlu, G, Sevinç, İ, Dikkat Eksikliği/Hiperaktivite Bozukluğu Tanılı Çocuk ve Ergenlerde Yeme ve Uyku Alışkanlıklarının Değerlendirilmesi, Celal Bayar Üniversitesi Sağlık Bilimleri Enstitüsü Dergisi, 2021, 8(1), 122-128.

27. Cook, B.G, Li, D, Heinrich, K.M, Obesity, physical activity, and sedentary behavior of youth with learning disabilities and ADHD, Journal of Learning Disabilities, 2015, 48(6), 563-576.

http://edergi.cbu.edu.tr/ojs/index.php/cbusbed isimli yazarın CBU-SBED başlıklı eseri bu Creative Commons Alınt1-Gayriticari4.0 Uluslararası Lisansı ile lisanslanmıștır. 